\title{
Electrochemical Corrosion Resistance and Electrical Conductivity of Three-Dimensionally Interconnected Graphene-Reinforced Cu Composites
}

\author{
Xue $\mathrm{Li}^{1}$, Ateeq Ahmed ${ }^{1}$, and Byung-Sang Choi ${ }^{1,2}$ \\ ${ }^{1}$ Department of Materials Science and Engineering, Chosun University, Gwangju 61452, Republic of Korea \\ ${ }^{2}$ Micro \& Nano Technologies, Inc., Gwangju 61452, Republic of Korea
}

\begin{abstract}
A three-dimensionally interconnected graphene-reinforced $\mathrm{Cu}$ (3Di $\mathrm{Gr}-\mathrm{Cu}$ ) composite was synthesized using a simple two-step process technique which involves the mechanical compaction of micronsized $\mathrm{Cu}$ particles followed by chemical vapor deposition (CVD) at $995{ }^{\circ} \mathrm{C}$. The microstructural properties of pure $\mathrm{Cu}$ and the 3Di $\mathrm{Gr}-\mathrm{Cu}$ composite were investigated by optical microscope, scanning electron microscope, and X-ray diffractometer. The electrical and corrosion behaviors of the 3Di Gr-Cu composite and $\mathrm{Cu}$ only, prepared by powder metallurgy (PM Cu), were studied and compared. The electrical conductivity (EC) of the 3Di Gr-Cu composites was found to be $38.8 \mathrm{MSm}^{-1}$ at a carbon content of $73 \mathrm{ppm}$, and exhibited a $12 \%$ higher $\mathrm{EC}$ than the $\mathrm{PM} \mathrm{Cu}$. Due to the interconnected graphene around the $\mathrm{Cu}$ grains, the corrosion current density and corrosion rate of the $3 \mathrm{Di} \mathrm{Gr}-\mathrm{Cu}$ composite decreased by $29 \%$ and $40 \%$, respectively, compared to the $\mathrm{PM}$ $\mathrm{Cu}$. The EC of the 3Di Gr-Cu composite depended on the carbon content. The improvement in the EC of the 3Di $\mathrm{Gr}-\mathrm{Cu}$ composite is attributed to the electron-carrying ability of the three-dimensionally interconnected graphene network (3DIGN) formed at the grain boundaries in the composite. The enhancement in corrosion resistance is due to the impermeability of graphene to various chemical species.
\end{abstract}

(Received May 17, 2021; Accepted August 11, 2021)

Keywords: 3Di Gr-Cu, CVD, electrochemical corrosion resistance, electrical conductivity

\section{Introduction}

Graphene, with its perfect honeycomb structure, is a twodimensional (2D) material comprised of a single layer of carbon atoms arranged in a hexagonal lattice [1-4]. With its first exfoliation from graphite in 2004, graphene launched a new era in 2D nanomaterial research because of its extraordinary physical, mechanical, electrical, and optical properties [5-8].

Several studies have attempted to improve the mechanical, thermal, and electrical properties of metal matrices by introducing graphene as a nanofiller [9-15]. Wang et al. [16] prepared graphene-reinforced copper matrix composites using high-pressure sintering and showed that the optimum product could be obtained using $0.5 \mathrm{wt} \%$ graphene, resulting high in yield stress, thermal and electrical conductivities, and corrosion resistance. Chen et al. [17] dispersed graphene

\footnotetext{
- Xue Li: 박사과정, Ateeq Ahmed: 연구원, Byung-Sang Choi: 교수 *Corresponding Author: Byung-Sang Choi [Tel: +82-10-3094-4253, E-mail: bschoi@chosun.ac.k] Copyright (c) The Korean Institute of Metals and Materials
}

nanoplatelets (GNPs) into a copper matrix, and investigated the effects of graphene on the mechanical, thermal, electrical, and tribological properties of the samples, which were prepared by mixing at the molecular-level and spark plasma sintering. Their experiment showed that the electrical properties of the copper matrix were adversely affected, possibly because of the nonuniform dispersion of the GNPs. Wei et al. [18] fabricated $\mathrm{Cu}$-graphene nanosheet composites at a relatively low temperature $\left(800{ }^{\circ} \mathrm{C}\right)$ using a hot-pressing method and observed a rough and uneven fracture surface, indicating that the graphene nanosheets were heterogeneously dispersed in the $\mathrm{Cu}$ matrix, resulting in anisotropic electrical and thermal behaviors.

Many researchers [19-21] have fabricated graphenereinforced metal matrix composites using dispersion methods. However, dispersion methods have the following two challenges; (i) a uniform dispersion of graphene in the metal matrix requires overcoming the high-density difference between graphene $\left(\sim 2.25 \mathrm{~g} \mathrm{~cm}^{-3}\right)$ and copper $\left(\sim 8.960 \mathrm{~g} \mathrm{~cm}^{-3}\right)$ and (ii) a sufficient amount of interfacial strength must be 
achieved between the graphene and the metal matrix [22]. To overcome those problems, we used a simple two-step fabrication process to prepare a three-dimensionally interconnected graphene-reinforced $\mathrm{Cu}$ (3Di Gr-Cu) composite [23]. The micron-sized $\mathrm{Cu}$ particles were first compacted into a disc (compaction process), and then graphene was introduced at the grain boundaries through the CVD process. This simple and economical method was used to synthesize a 3Di $\mathrm{Gr}-\mathrm{Cu}$ composite with uniformly dispersed graphene surrounding the grains of the metal matrix. The mechanical and thermal properties of the 3Di $\mathrm{Gr}-\mathrm{Cu}$ composite were previously described [23].

The present research is aimed at exploring the electrical and chemical behaviors of the 3Di Gr-Cu composite, and the influence of graphene on the properties of the metal matrix by analyzing the microstructure, electrical properties, and corrosion behavior of the 3Di $\mathrm{Gr}-\mathrm{Cu}$ composite.

\section{Materials and Methodology}

\subsection{Synthesis of 3Di Gr-Cu Composites}

$\mathrm{Cu}$ powder $(99.5 \%$ purity) with $14-25 \mu \mathrm{m}$ spheroidal particles was purchased from Sigma Aldrich. To make compact discs with diameters and thicknesses of $\sim 15 \mathrm{~mm}$ and $\sim 1 \mathrm{~mm}$, respectively, the powder was compacted in a double hydraulic press under a compaction pressure of $112 \mathrm{MPa}$ to achieve the maximum density of the composite, as determined in our previous work [23]. The 3Di Gr-Cu composite was synthesized following the experimental conditions shown in Figure 1(a). The fabrication scheme to produce the 3Di $\mathrm{Gr}-\mathrm{Cu}$ composite and $\mathrm{PM} \mathrm{Cu}$ is shown in
Figure 1 (b). For comparison, a $\mathrm{Cu}$ only sample was prepared via powder metallurgy ( $\mathrm{PM} \mathrm{Cu}$ ) under the same conditions, except that methane was not introduced into the system (i.e., without CVD).

\subsection{Microstructural Characterization}

For the microstructural examination, polished and cleaned samples of the 3Di Gr-Cu composite and PM Cu were etched in mixed solutions of $1 \mathrm{M} \mathrm{FeCl}_{3}$ and $0.1 \mathrm{M} \mathrm{HCl}$ to reveal the surface microstructure, which was observed using an optical microscope (OM). A structural phase investigation was conducted via $\mathrm{x}$-ray diffraction using $\mathrm{Cu} \mathrm{K} \alpha 1$ radiation with a wavelength $(\lambda)$ of $0.154060 \mathrm{~nm}$ in the scan range of $5^{\circ}-$ $100^{\circ}$. To reveal the 3-dimensionally interconnected graphene network (3DIGN), the 3Di Gr-Cu composite sample was placed into the etchant for more than $12 \mathrm{~h}$. When the $\mathrm{Cu}$ was completely etched away, the remaining 3DIGN was washed carefully with deionized (DI) water several times. To avoid structural damage due to capillary forces the freeze-drying method was employed to obtain free-standing 3DIGN [24].

\subsection{Corrosion Tests}

The anticorrosion behavior was evaluated using potentiodynamic polarization experiments, performed on the $\mathrm{PM} \mathrm{Cu}$ and 3Di Gr-Cu composite in a $3.5 \mathrm{wt} \% \mathrm{NaCl}$ solution using a potentiostat (BioLogic VMP3). A copper wire was attached using a conductive adhesive to the back of the specimen, which was then mounted with an epoxy resin. The mounted specimen was then mechanically polished using 400-2000 grit $\mathrm{SiC}$ abrasive papers.

After fine polishing, each specimen was cleaned (a)

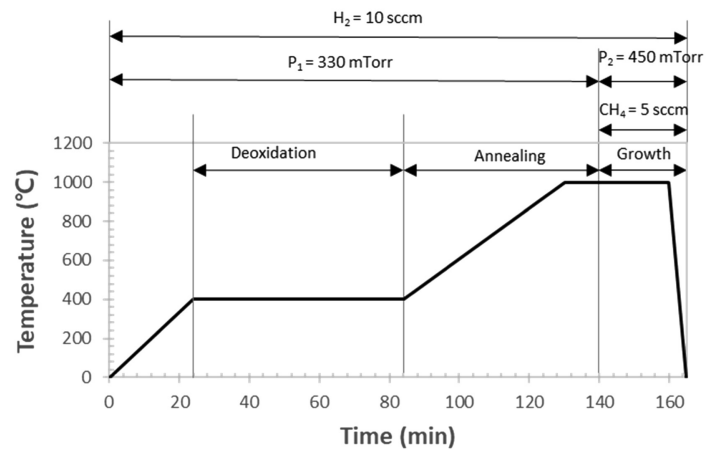

(b)

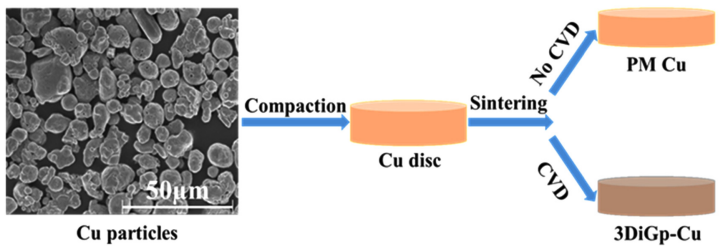

Fig. 1. Fabrication of PM Cu and 3Di Gr-Cu composite: (a) experimental conditions, and (b) a schematic showing the simple two-step process of powder compaction and CVD. 


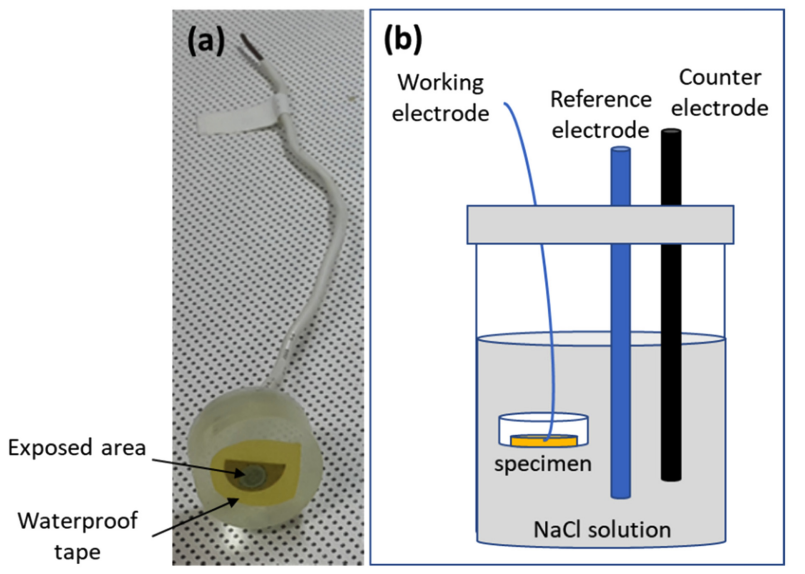

Fig. 2. Schematic of the potentiodynamic polarization experiment; (a) a specimen and (b) an experimental setup

ultrasonically with DI water and alcohol for $1 \mathrm{~min}$ and dried with $\mathrm{N}_{2}$ gas. A working electrode with an exposed area of $0.28 \mathrm{~cm}^{2}$ on the mounted specimen was marked and the rest of the area was masked with waterproof tape as shown in Figure 2(a). A three-electrode electrochemical cell was constructed using the specimen as the working electrode, a saturated calomel electrode as the reference electrode, and graphite as the counter electrode as shown in Figure 2(b). Experiments were performed at $25^{\circ} \mathrm{C}$ in $3.5 \mathrm{wt} \% \mathrm{NaCl}$ solution, which was degassed earlier with nitrogen gas for 1 $\mathrm{h}$. The corrosion potential $\left(\mathrm{E}_{\text {corr }}\right)$ and corrosion current density $\left(\mathrm{I}_{\text {corr }}\right)$ were determined from the polarization curves using the Tafel extrapolation technique. The measurements were obtained in $1800 \mathrm{~s}$ at a scanning rate of $1 \mathrm{mV} / \mathrm{s}$ by sweeping the voltage range from $-0.3 \mathrm{~V}$ to $+0.0 \mathrm{~V}$.

A hydrogen-assisted corrosion (HAC) experiment was also performed for the PM $\mathrm{Cu}$ and 3Di Gr-Cu composite in a corrosive electrolyte. To prepare a strong acidic electrolyte solution $(\mathrm{pH}=0.7), \quad 0.3 \mathrm{~g} \cdot \mathrm{mL}^{-1}$ ammonium persulfate $\left(\left(\mathrm{NH}_{4}\right)_{2} \mathrm{~S}_{2} \mathrm{O}_{8}\right)$ was dissolved in DI water and a small amount of nitric acid $\left(\mathrm{HNO}_{3}\right)$ added to adjust the $\mathrm{pH}$. The disc samples of PM Cu and 3Di Gr-Cu were cut into halves and weighed by an analytical balance with a precision of $0.000 \mathrm{~g}$. The specimen in the electrolyte served as the cathode and the platinum served as the anode in the electrochemical cell. The current of the pulse silicon-controlled rectifier was adjusted to $8.5 \mathrm{~A}$. Every $2 \mathrm{~min}$, the specimen was removed, washed with DI water, dried, and weighed to determine the weight loss as a function of time. A higher weight loss indicates a higher HAC [25]. At least five samples each from the $\mathrm{PM} \mathrm{Cu}$ and 3Di Gr-Cu composite were tested for corrosion, and the average values were used for the analyses.

\subsection{Electrical Conductivity (EC) Measurements}

The ECs of $\mathrm{PM} \mathrm{Cu}$ and 3Di $\mathrm{Gr}-\mathrm{Cu}$ composite were measured at $\sim 20^{\circ} \mathrm{C}$ using a four-point probe contact (FPPC) method [26]. The specimen ( $\mathrm{L} 10 \mathrm{~mm} \times \mathrm{W} 5 \mathrm{~mm} \times \mathrm{T} 1 \mathrm{~mm}$ ) was cut from the disc sample and the surface was gently polished. Four aluminum wires were attached to the polished surface of each sample using conductive epoxy glue which was cured at $150{ }^{\circ} \mathrm{C}$ for $30 \mathrm{~min}$ in an $\mathrm{H}_{2}$ atmosphere. Next, the sample was mounted on a circuit board (shown in Figure 9(a)) and the assembly was positioned on the device for measuring direct-current electrical resistivity. The voltage (V) between the inner terminals was measured by varying the current (I) between the outer terminals to obtain the I-V characteristic curve. The resistances $(R)$ of $\mathrm{PM} \mathrm{Cu}$ and 3Di $\mathrm{Gr}-\mathrm{Cu}$ composite were obtained by analyzing the resulting I$\mathrm{V}$ curve according to Ohm's law [27]. The EC $(\sigma)$ was calculated as follows [28]:

$$
\sigma=\frac{l}{\rho}=\frac{l}{R A}
$$

where $\sigma$ denotes the EC, $\rho$ is the resistivity, $l$ is the interelectrode distance, $R$ denotes the slope of the $\mathrm{I}-\mathrm{V}$ curve, and $A$ is the cross-sectional area of the sample. The EC tests were performed for five specimens to ensure the repeatability and reproducibility of the measurements.

\section{Results and Discussion}

\subsection{Microstructure of 3Di Gr-Cu Composite}

Figure 3 shows the OM images of the PM Cu and 3Di Gr$\mathrm{Cu}$ composite. The average grain sizes of the $\mathrm{PM} \mathrm{Cu}$ (Figure 3(a)) and the 3Di Gr-Cu composite (Figure 3(b)) were found to be $\sim 50 \mu \mathrm{m}$ and $\sim 40 \mu \mathrm{m}$, respectively. The difference in grain size could be attributed to the formation of graphene around the $\mathrm{Cu}$ grains in the 3Di $\mathrm{Gr}-\mathrm{Cu}$ composite. The formation of graphene at the grain boundaries acted as a diffusion barrier, thus hindering the further growth of $\mathrm{Cu}$ grains during the CVD process $[23,29]$. 

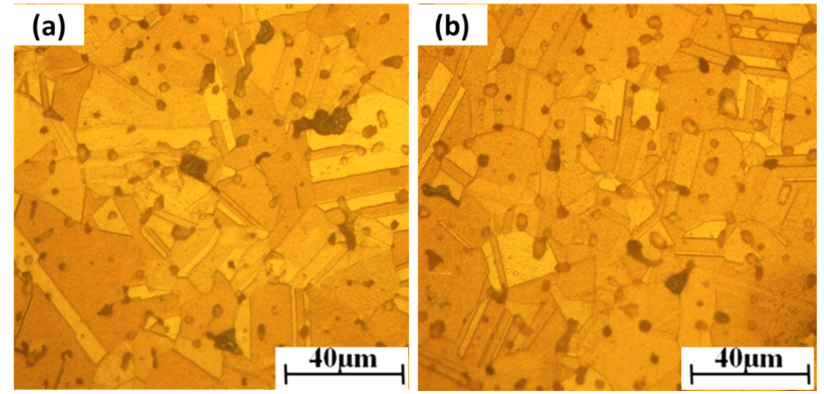

Fig. 3. OM images of PM Cu (a) and 3Di Gr-Cu composite (b).

Figure 4(a) shows the X-ray diffraction (XRD) spectra of the $\mathrm{PM} \mathrm{Cu}$ and 3Di $\mathrm{Gr}-\mathrm{Cu}$ composite. Three distinct characteristic reflection peaks located at $43.31^{\circ}, 50.34^{\circ}$, and $74.14^{\circ}$ were observed and could be respectively assigned to the (111), (200), and (220) crystal planes (JCPDS No.-040836). Figure 4(b) shows an SEM image of the free-standing
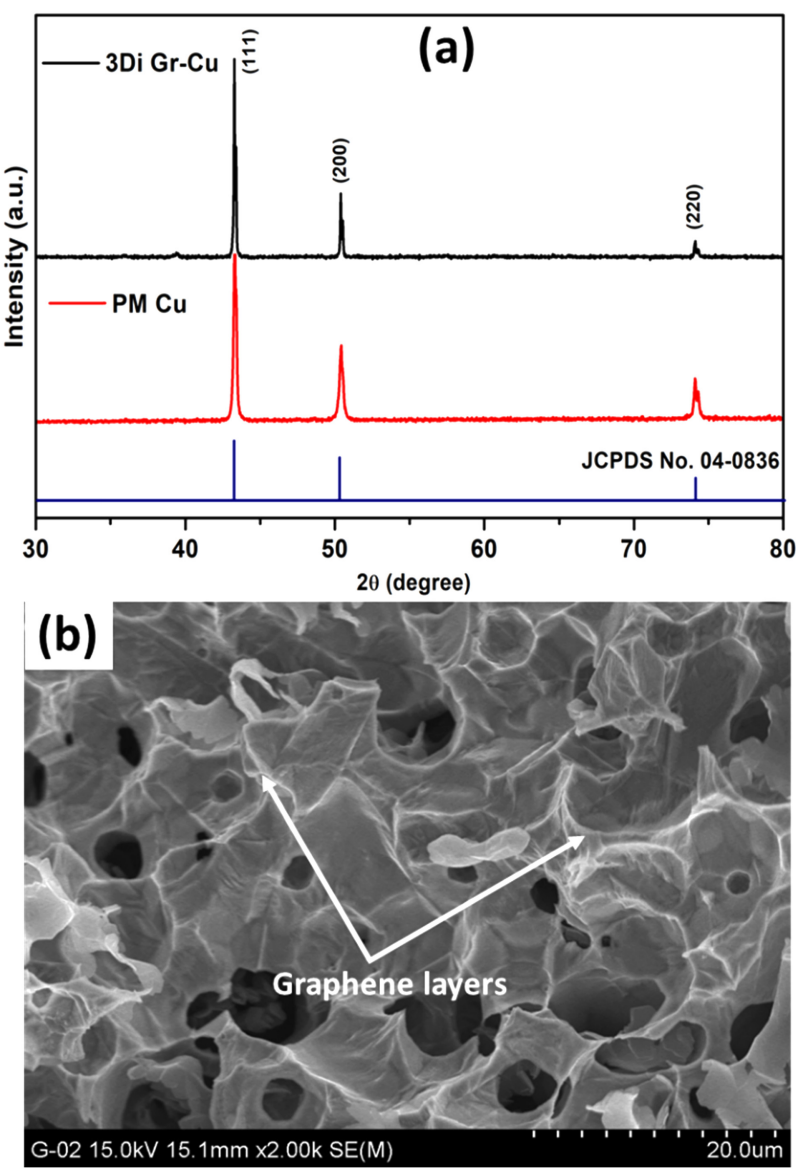

Fig. 4. (a) XRD patterns of $\mathrm{PM} \mathrm{Cu}$ and $3 \mathrm{DiGr} \mathrm{Cu}$ composite (b) SEM image of the 3-dimensionally interconnected graphene network (3DIGN) 3-dimensional (3D) graphene obtained after freeze-drying. The 3D structure of graphene in Figure 4(b) indicates that the graphene was formed at the grain boundaries of various shaped and sized $\mathrm{Cu}$ grains, thus confirming the three dimensionally interconnected graphene network (3DIGN) in the 3Di Gr-Cu composite. The $3 \mathrm{DIGN}$ is expected to impart excellent thermal, chemical, and mechanical properties to the 3Di Gr-Cu composite [23,30].

\subsection{Corrosion Analysis}

\subsubsection{Electrochemical corrosion (ECC)}

Figure 5 shows the potentiodynamic polarization curves of the $\mathrm{PM} \mathrm{Cu}$ and 3Di Gr-Cu composite. Compared with the $\mathrm{PM} \mathrm{Cu}$, the polarization curve of the 3Di Gr-Cu composite moved in the positive direction of the potential (upward in Figure 5), indicating a higher corrosion potential $\left(\mathrm{E}_{\text {corr }}\right)[31$, 32]. The current density $\left(\mathrm{I}_{\text {corr }}\right)$ and the corrosion potential $\left(\mathrm{E}_{\text {corr }}\right)$ were measured using Tafel analysis, in which the extrapolated Tafel curves (representing cathodic and anodic currents) intersect with each other to give $\mathrm{I}_{\text {corr }}$ and $\mathrm{E}_{\text {corr }}$ The $\mathrm{E}_{\text {corr }}$ of the 3Di Gr-Cu composite was $-0.185 \mathrm{~V}$, which was higher than that of the $\mathrm{PM} \mathrm{Cu}(-0.220 \mathrm{~V})$.

In corrosion thermodynamics, the higher the value of $\mathrm{E}_{\text {corr }}$ the better the anticorrosion properties of a material [31,32]. Similarly, a low $\mathrm{I}_{\text {corr }}$ value indicates better anticorrosion properties (higher corrosion resistance) [33]. In corrosion kinetics, the corrosion rate $(\mathrm{CR})$ is directly proportional to $\mathrm{I}_{\text {corr }}$; hence, a higher $\mathrm{I}_{\text {corr }}$ value would lead to a higher $\mathrm{CR}$.

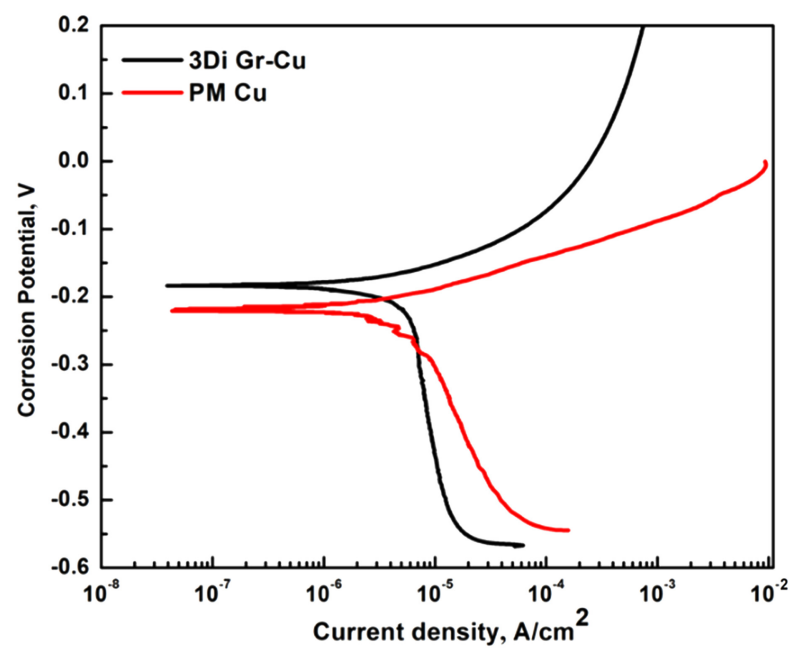

Fig. 5. Potentiodynamic polarization curves of $\mathrm{PM} \mathrm{Cu}$ and $3 \mathrm{DiGr}$ $\mathrm{Cu}$ composite in $3.5 \mathrm{wt} \% \mathrm{NaCl}$ solution. 
Table 1. Electrochemical corrosion parameters obtained from the polarization curves of $\mathrm{PM} \mathrm{Cu}$ and 3Di Gr-Cu composite in $3.5 \mathrm{wt} \%$ $\mathrm{NaCl}$ solution.

\begin{tabular}{cccc}
\hline Specimen type & $\mathrm{I}_{\text {corr }} \mu \mathrm{A} \cdot \mathrm{cm}^{-2}$ & $\mathrm{E}_{\text {corr }}, \mathrm{V}$ & $\mathrm{CR}, \mathrm{mm} \cdot$ year $^{-1}$ \\
\hline $\mathrm{PM} \mathrm{Cu}$ & $2.691 \pm 0.03$ & $-0.220 \pm 0.003$ & 1.33 \\
3Di Gr-Cu & $1.914 \pm 0.02$ & $-0.185 \pm 0.003$ & 0.95
\end{tabular}

Faraday's law of electrolysis was employed to deduce the CR from the value of $I_{\text {corr }}$ using the following equation [34]:

$$
C R\left(m^{\prime} \cdot \text { year }^{-1}\right)=\left[\left(0.129 \times I_{\text {corr }} \times M\right) /(n \times D)\right]
$$

where $M$ is the atomic weight of $\mathrm{Cu}(63.5 \mathrm{~g}), \mathrm{I}_{\text {corr }}$ is expressed in $\mu \mathrm{A} \cdot \mathrm{cm}^{-2}$ (Table 1), $n$ is the valency of $\mathrm{Cu}(2)$, and $D$ is the density $\left(\mathrm{g} \cdot \mathrm{cm}^{-3}\right)$ of the corroding material. The densities of PM Cu and 3Di Gr-Cu $\left(8.27\right.$ and $8.26 \mathrm{~g} \cdot \mathrm{cm}^{-3}$, respectively) were measured according to Archimedes' principle [35]. CRs for the PM Cu and 3Di Gr-Cu composite were measured to be $1.33 \mathrm{~mm} \cdot \mathrm{year}^{-1}$ and $0.95 \mathrm{~mm} \cdot \mathrm{year}^{-1}$, respectively.

Table 1 presents the electrochemical corrosion parameters obtained from the polarization curves, shown in Figure 5. The decrease in $\mathrm{I}_{\text {corr }}$ and $\mathrm{CR}$ for the 3Di Gr-Cu composite as compared to $\mathrm{PM} \mathrm{Cu}$ proves that the 3DIGN provides effective protection against corrosion of the metal matrix.

Because graphene is highly impermeable to ions and molecules, the interconnected graphene at the grain boundaries acts as a charge transfer inhibitor [36] which impedes the free flow of $\mathrm{Cu}^{+}$ions and $\mathrm{H}_{2} / \mathrm{O}_{2}$ across the $\mathrm{Cu}-$ electrolyte interface, and thus reducing the surface area exposed to the corrosion solution [31]. Therefore, the formation of the 3DIGN can effectively reduce the reaction speed and CR of the metal matrix, resulting in the excellent corrosion resistance of the $3 \mathrm{Di} \mathrm{Gr}-\mathrm{Cu}$ composite.

\subsubsection{Hydrogen-assisted corrosion (HAC)}

Figure 6(a) illustrates the experimental setup for the HAC tests. During the experiment, a positive potential was applied to the anode $(\mathrm{Pt})$, and hydrogen was generated through electrochemical reactions as follows [36]:

$$
\begin{aligned}
& \mathrm{H}_{2} \mathrm{O}+\mathrm{e}^{-} \rightarrow \mathrm{H}^{+}+\mathrm{OH}^{-} \\
& 2 \mathrm{H}^{+}+\mathrm{e}^{-} \rightarrow \mathrm{H}_{2}
\end{aligned}
$$

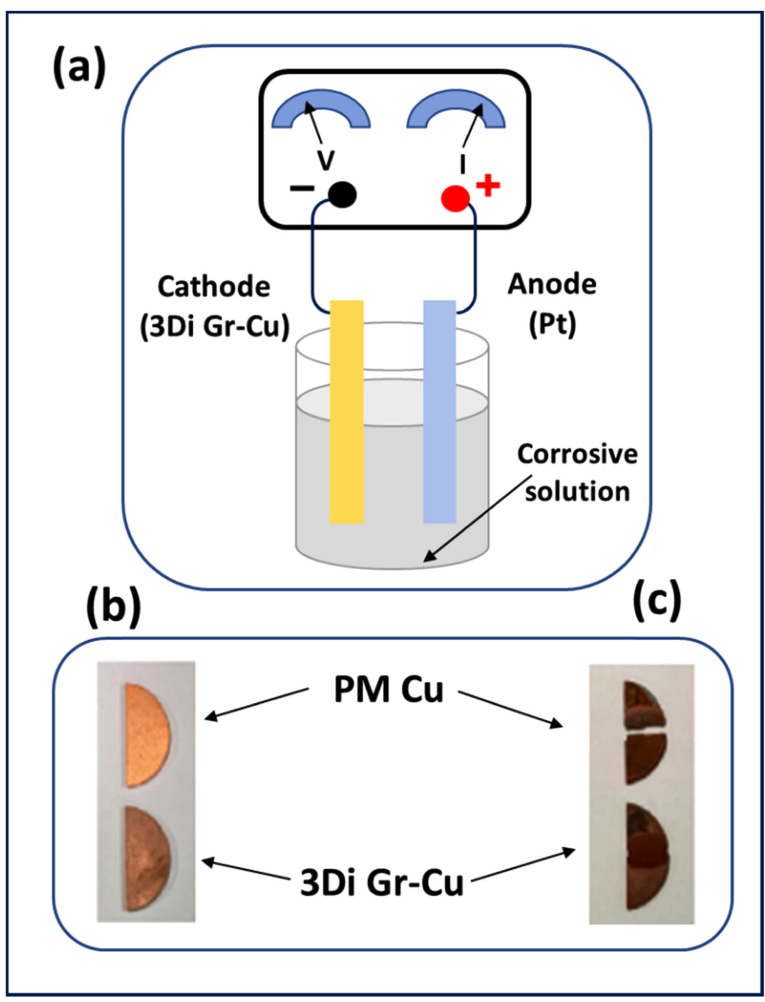

Fig. 6. (a) A schematic of the experimental setup for HAC, (b) before, and (c) after the HAC experiment for PM Cu and 3Di Gr$\mathrm{Cu}$ composite.

Most of the atomic hydrogen spontaneously recombined to form molecular hydrogen $\left(\mathrm{H}_{2}\right)$, while the remaining portion of the atomic hydrogen diffused into the lattice sites and remained in the material (cathode). However, the diffusivity of atomic hydrogen depends mainly on the nature of the material.

Many studies have shown that graphene is impermeable to atomic hydrogen [36-38]. Therefore, the 3DIGN in 3Di Gr$\mathrm{Cu}$ composite can function as an effective barrier to atomic hydrogen. In contrast, $\mathrm{PM} \mathrm{Cu}$ is not capable of blocking atomic hydrogen; hence, the corrosion reaction was accelerated by the diffusion of atomic hydrogen at the cathode [25]. In the results shown in Figures 6(b) and (c), before and after the HAC experiment, the PM Cu exhibits more corrosion than the 3Di $\mathrm{Gr}-\mathrm{Cu}$ composite. Figure 7 shows the weight losses of the specimens vs. time as a result of HAC.

In the experiment, from the beginning to $10 \mathrm{~min}$, the weight losses observed for PM $\mathrm{Cu}$ and 3Di $\mathrm{Gr}-\mathrm{Cu}$ did not differ significantly. This is because the surfaces of both 


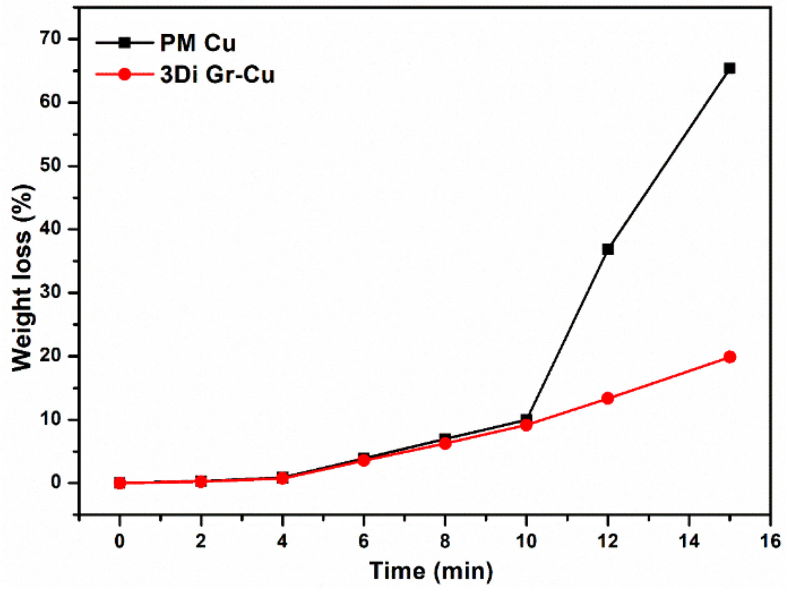

Fig. 7. Weight loss of $\mathrm{PM} \mathrm{Cu}$ and $3 \mathrm{Di} \mathrm{Gr}-\mathrm{Cu}$ composite vs. time during HAC experiment.

samples were polished, thereby directly exposing the metal surface to HAC. However, after $\sim 10 \mathrm{~min}$, the difference in weight loss (\%) between the $\mathrm{PM} \mathrm{Cu}$ and 3Di $\mathrm{Gr}-\mathrm{Cu}$ composite grew large, as shown in Figure 7. At the end of the experiment ( $\sim 15 \mathrm{~min})$, the weight losses for the $\mathrm{PM} \mathrm{Cu}$ and the $3 \mathrm{D} \mathrm{Gr}-\mathrm{Cu}$ composite were calculated to be $67 \%$ and $20 \%$, respectively. Notably, the 3Di Gr-Cu exhibited less weight loss than the PM Cu mainly due to the 3DIGN in the 3Di Gr$\mathrm{Cu}$ composite. The 3DIGN, acting as a barrier, prevents hydrogen penetration (diffusivity) into the metal matrix, thereby reducing the HAC. Nam et al. [36] reported similar experimental results, that the graphene-coated copper exhibited a much lower HAC ratio (3.0\%) than bare copper $(10.1 \%)$.

Figure 8 shows $\mathrm{OM}$ images of the PM Cu and 3Di Gr-Cu composite samples after the HAC experiment. The dotted white circles in Figure 8 show HAC pits at the surface. A greater volume fraction of pits with an average diameter of $70 \mu \mathrm{m}$ can be observed in the PM Cu in Figure 8(a), while a relatively smaller volume fraction of pits with an average diameter of $20 \mu \mathrm{m}$ is seen for 3Di Gr-Cu in Figure 8(b). This result again confirms that the 3 DIGN acted as a barrier to block hydrogen into the metal matrix.

\subsection{Electrical Conductivity (EC)}

The ECs of the samples containing different amounts of carbon were measured, and the results are shown in Figure 9(a). When the amount of carbon was less than $73 \mathrm{ppm}$, the graphene network may not have been continuous in the 3Di $\mathrm{Gr}-\mathrm{Cu}$ composite. The continuity of the graphene network reached its maximum at $\sim 73 \mathrm{ppm}$ of carbon, resulting in a higher EC (38.8 MS $\left.\cdot \mathrm{m}^{-1}\right)$. The gradual decrease in EC above $73 \mathrm{ppm}$ of carbon could be due to the decrease in the electron mean-free path, caused by the increasing number of graphene layers. Nevertheless, the $\mathrm{EC}$ of the 3Di $\mathrm{Gr}-\mathrm{Cu}$ composite even up to $100 \mathrm{ppm}$ of carbon was higher than that of the PM $\mathrm{Cu}$. The carbon contents in the 3Di Gr-Cu composite were measured as a function of density using an ELTRA CS-2000 analyzer with $\pm 0.3 \mathrm{ppm}$ precision.

Figure 9(b) presents the EC of the PM Cu and 3Di Gr-Cu composite in the directions parallel $\left(\mathrm{R}_{\|}\right)$and normal $\left(\mathrm{R}_{\perp}\right)$ to the rolling directions after $50 \%$ coldwork. The EC of the 3Di Gr-Cu composite increased by $12.14 \%$ and $10.25 \%$ in the $\mathrm{R}$ \| and $\mathrm{R}_{\perp}$ directions, respectively, compared with those of the $\mathrm{PM} \mathrm{Cu}$. This is because the grains were elongated and had
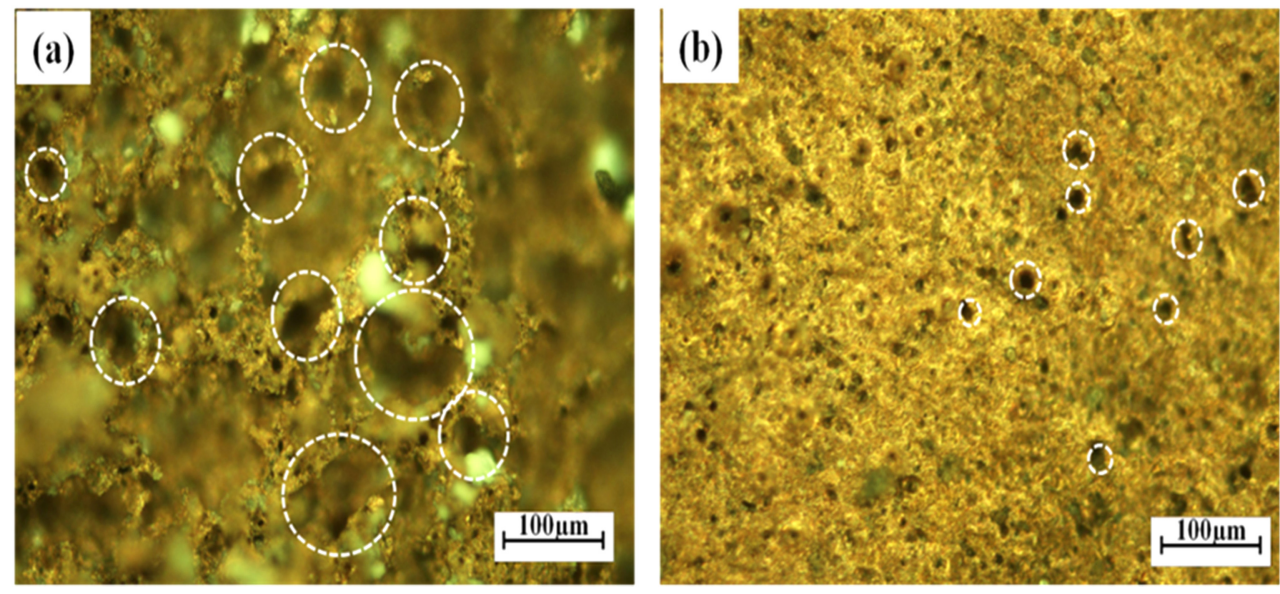

Fig. 8. OM images of (a) PM Cu and (b) 3Di Gr-Cu composite after HAC experiment. 

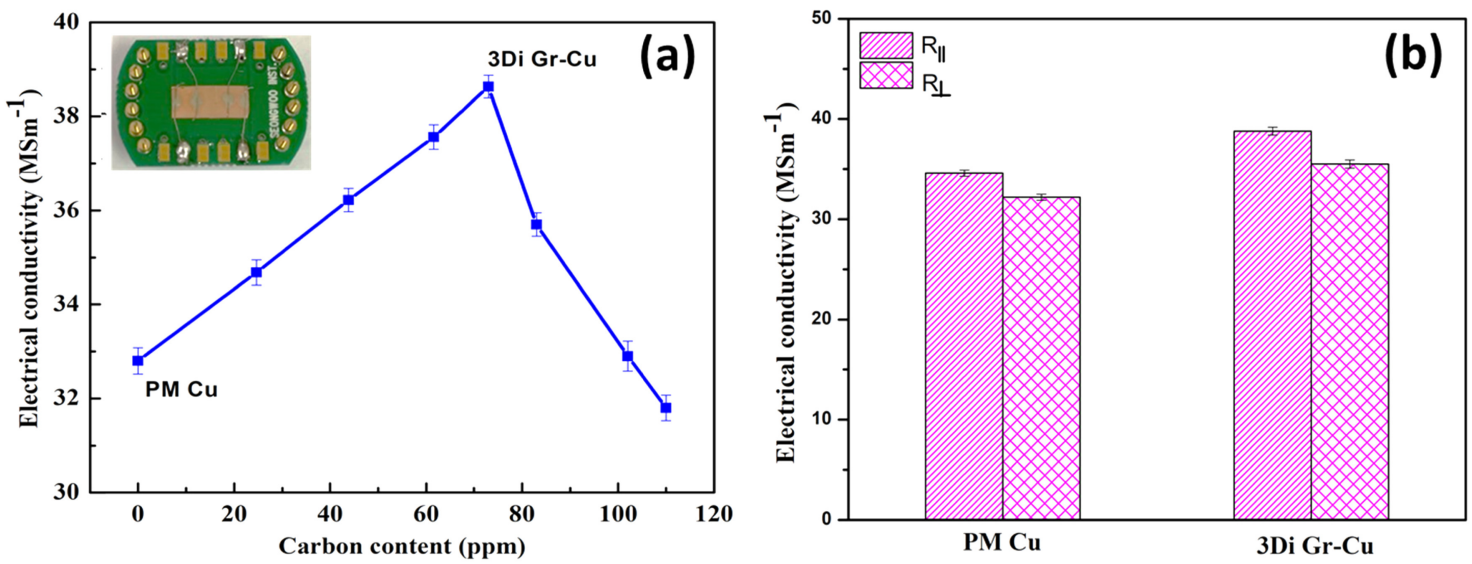

Fig. 9. (a) EC vs. carbon contents in the 3Di Gr-Cu composite parallel to the rolling direction, (b) electrical conductivities of the PM Cu and $3 \mathrm{Di} \mathrm{Gr}-\mathrm{Cu}$ composite along directions parallel $\left(\mathrm{R}_{\|}\right)$and normal $\left(\mathrm{R}_{\perp}\right)$ to the rolling direction.

fewer grain boundaries in the $\mathrm{R}_{\|}$direction than in the $\mathrm{R}_{\perp}$ direction.

The 3D interconnected graphene in the 3Di $\mathrm{Gr}-\mathrm{Cu}$ composite provides an effective conduction channel for electron movement, thereby aiding electron mobility [39]. The 3D interconnected graphene and its excellent bonding with $\mathrm{Cu}$ at the interface enhances the $\mathrm{EC}$ of the 3Di Gr-Cu composite [40].

\section{Conclusions}

The microstructure, corrosion behavior, and electrical properties of the fabricated 3Di Gr-Cu composite and $\mathrm{PM} \mathrm{Cu}$ were characterized and can be summarized as follows:

- The formation of 3D interconnected graphene in the $\mathrm{Cu}$ matrix reduced the corrosion current density and CR by $29 \%$ and $40 \%$, respectively, as compared to the PM Cu. This could be attributed to the $3 \mathrm{DIGN}$ in the $3 \mathrm{Di} \mathrm{Gr}-\mathrm{Cu}$ composite. The 3DIGN provides high impermeability to ions and molecules, thus effectively blocking them in the 3Di Gr-Cu composite in the ECC experiment.

- The HAC experiment showed that the weight loss of the 3Di Gr-Cu composite was approximately one-third that of the PM Cu, mostly due to the interconnected graphene network, which blocked the penetration of atomic hydrogen into the composite.

- The EC of the 3Di Gr-Cu composite depended on the carbon content and was found to be highest at $38.8 \mathrm{MS} \cdot \mathrm{m}^{-1}$ with 73 ppm.

- The EC of 3Di $\mathrm{Gr}-\mathrm{Cu}$ composite was found to be approximately $12 \%$ higher than that of the PM Cu because the continuous graphene network effectively provided a conduction channel for electron movement.

\section{Acknowledgment}

This work was supported by funding from Chosun University, 2019.

\section{Declaration of Competing Interest}

\section{References}

1. S. Stankovich, D. A. Dikin, G. H. B. Dommett, K. M. Kohlhaas, E. J. Zimney, E. A. Stach, R. D. Piner, S. T. Nguyen, and R. S. Ruoff, Nature 442, 282 (2006).

2. X. Huang, X. Qi, F. Boey, and H. Zhang, Chemical Society Reviews 41, 666 (2012).

3. A. K. Geim and K. S. Novoselov, Nanoscience and technology: a collection of reviews from nature journals, 11, World Scientific, Place PUblished (2010).

4. W. Lu, P. Soukiassian, and J. Boeckl, MRS bulletin 37, 1119 (2012).

5. L. Lin, B. Deng, J. Sun, H. Peng, and Z. Liu, Chemical reviews 118, 9281 (2018).

6. H. O. Pierson, Handbook of carbon, graphite, diamonds and fullerenes: processing, properties and applications, 
William Andrew (2012).

7. K. M. Shahil and A. A. Balandin, Solid state communications 152, 1331 (2012).

8. C. Lee, X. Wei, J. W. Kysar, and J. Hone, science 321, 385 (2008).

9. P. Hidalgo-Manrique, X. Lei, R. Xu, M. Zhou, I. A. Kinloch, and R. J. Young, Journal of materials science $\mathbf{5 4}$ 12236 (2019).

10. H. P. Kumar and M. A. Xavior, Procedia Engineering 97, 1033 (2014).

11. A. Nieto, A. Bisht, D. Lahiri, C. Zhang, and A. Agarwal, International Materials Reviews 62, 241 (2017).

12. M. Tabandeh-Khorshid, A. Kumar, E. Omrani, C. Kim, and P. Rohatgi, Composites Part B: Engineering 183, 107664 (2020).

13. A. K. Kasar, G. Xiong, and P. L. Menezes, JOM 70, 829 (2018).

14. H. Lee, K. Kim, and O. Song, Korean Journal of Metals and Materials 57, 456 (2019).

15. V. G. Konakov, O. Y. Kurapova, and I. Y. Archakov, Metals and Materials International 26, 1899 (2020).

16. J. Wang, L.-n. Guo, W.-m. Lin, J. Chen, S. Zhang, T.-t. Zhen, and Y.-y. Zhang, New Carbon Materials 34, 161 (2019).

17. F. Chen, J. Ying, Y. Wang, S. Du, Z. Liu, and Q. Huang, Carbon 96, 836 (2016).

18. B. W. Wei, D. Qu, C. F. Hu, F. Z. Li, T. L. Zhou, R. J. Xie, and Z. M. Zhou, Advanced Materials Research 833, 310 (2014).

19. D. Zhang and Z. Zhan, Journal of Alloys and Compounds 658, 663 (2016).

20. S. C. Tjong, Materials Science and Engineering: $R$ : Reports 74, 281 (2013).

21. J. M. Schnorr and T. M. Swager, Chemistry of Materials 23 , 646 (2011).

22. Y. Chen, X. Zhang, E. Liu, C. He, Y. Han, Q. Li, P. Nash, and N. Zhao, Journal of Alloys and Compounds 688, 69 (2016).

23. X. Li, T. A. Ring, and B.-S. Choi, Korean Journal of Metals and Materials 57, 529 (2019).
24. Y. Ding, H. Chen, Z. Li, H. Ren, X. Tang, J. Yin, Y. Jiang, and P. Zhang, Novel Nanomaterials-Synthesis and Applications, IntechOpen, Place PUblished (2017).

25. Y. Fan, Y. Huang, B. Cui, and Q. Zhou, Surface and Coatings Technology 374, 610 (2019).

26. Y. Singh, International journal of modern physics: Conference series 22, 745 (2013)

27. E. Palmes and R. Lindenboom, Analytical Chemistry 51, 2400 (1979).

28. M. M. Gudarzi, M. H. M. Moghadam, and F. Sharif, Carbon 64, 403 (2013).

29. S.-R. Kawk, T. A. Ring, and B.-S. Choi, Journal of Industrial and Engineering Chemistry 70, 484 (2019).

30. Y. Jo, X. Li, D. Cho, and B.-S. Choi, Journal of Advanced Engineering Technology 12, 091 (2019).

31. A. Kamboj, Y. Raghupathy, M. Rekha, and C. Srivastava, JOM 69, 1149 (2017)

32. P. Hidalgo-Manrique, X. Lei, R. Xu, M. Zhou, I. A. Kinloch, and R. J. Young, Journal of materials science 54, 12236 (2019).

33. P. Rojas, R. Vera, C. Martínez, and M. Villarroel, International Journal of Electrochemical Science 11, 4701 (2016).

34. Y. Raghupathy, K. A. Natarajan, and C. Srivastava, Materials Science and Engineering: B 206, 1(2016).

35. R. C. Schultz, R. F. Dolezal, and J. Nolan, Annals of plastic surgery 16, 98 (1986).

36. T.-H. Nam, J.-H. Lee, S.-R. Choi, J.-B. Yoo, and J.-G. Kim, International journal of hydrogen energy 39, 11810 (2014).

37. P. Zhou, W. Li, X. Zhu, Y. Li, X. Jin, and J. Chen, Journal of the Electrochemical Society 163, D160 (2016).

38. S. Hu, M. Lozada-Hidalgo, F. Wang, A. Mishchenko, F. Schedin, R. Nair, E. Hill, D. Boukhvalov, M. Katsnelson, and R. Dryfe, Nature 516, 227 (2014).

39. Z. Spitalsky, D. Tasis, K. Papagelis, and C. Galiotis, Progress in polymer science 35, 357 (2010).

40. M. Wang, L.-D. Wang, J. Sheng, Z.-Y. Yang, Z.-D. Shi, Y.P. Zhu, J. Li, and W.-D. Fei, Journal of Alloys and Compounds 798, 403(2019). 